\title{
A combined approach of complex eigenvalue analysis and design of experiments (DOE) to study disc brake squeal
}

\author{
M. Nouby $^{1^{*}}$, D. Mathivanan ${ }^{2 *}$, K. Srinivasan ${ }^{1}$ \\ ${ }^{1}$ AU/FRG Institute for CAD/CAM, Anna University, Chennai-600025, India \\ ${ }^{2}$ Director of CAE Infotech, Chennai-600020, India \\ E-mails:(noubyluxor@gmail.com (M. Nouby),mathvan@yahoo.com (D. Mathivanan); “Corresponding authors)
}

\begin{abstract}
This paper proposes an approach to investigate the influencing factors of the brake pad on the disc brake squeal by integrating finite element simulations with statistical regression techniques. Complex eigenvalue analysis (CEA) has been widely used to predict unstable frequencies in brake systems models. The finite element model is correlated with experimental modal test. The 'input-output' relationship between the brake squeal and the brake pad geometry is constructed for possible prediction of the squeal using various geometrical configurations of the disc brake. Influences of the various factors namely; Young's modulus of back plate, back plate thickness, chamfer, distance between two slots, slot width and angle of slot are investigated using design of experiments (DOE) technique. A mathematical prediction model has been developed based on the most influencing factors and the validation simulation experiments proved its adequacy. The predicted results show that brake squeal propensity can be reduced by increasing Young's modulus of the back plate and modifying the shape of friction material by adding chamfer on both sides of friction material and by introducing slot configurations. The combined approach of modeling brake squeal using CEA and DOE is found to be statistically adequate through verification trials. This combined approach will be useful in the design stage of the disc brake.
\end{abstract}

Keywords: Disc brake squeal, finite element analysis, experimental modal analysis, design of experiments

\section{Introduction}

Brake squeal is a noise problem caused by vibrations induced by friction forces that can induce a dynamic instability (Akay, 2002). During the braking operation, the friction between the pad and the disc can induce a dynamic instability in the system. Usually brake squeal occurs in the frequency range between 1 and $20 \mathrm{kHz}$. Squeal is a complex phenomenon, partly because of its strong dependence on many parameters and, partly, because of the mechanical interactions in the brake system. The mechanical interactions are considered to be very complicated because of nonlinear contact effects at the friction interface. The occurrence of squeal is intermittent or even random. Under certain conditions, even when the vehicle is brand new, it often generates squeal noise, which has been extensively studied with the goal of eliminating the noise. However, mechanistic details of squeal noise are not yet fully understood (Joe et al., 2008). Several theories have been formulated to explain the mechanisms of brake squeal, and numerous studies have been made with varied success to apply them to the dynamics of disc brakes (Kinkaid et al., 2003).

The reason for the onset of instability has been attributed to different reasons. Some of the major reasons are the change of the friction characteristic with the speed of the contact points (Ibrahim, 1994; Ouyang et al., 1998; Shin et al., 2002) the change of the relative orientation of the disk and the friction pads leading to a modification of the friction force (Millner, 1978), and a flutter instability which is found even with a constant friction coefficient (Chowdhary et al., 2001; Chakrabotry et al., 2002; Von Wagner et al., 2003; Von Wagner et al., 2004). In fact, recent literature reviews (Kinkaid et al., 2003; Papinniemi et al., 2002) have reported on the complexity and lack of understanding of the brake squeal problem.

Though much work was done on the issue of squeal, it requires continuous study and investigation to refine the prediction accuracy of finite element models of brake assemblies to give brake design engineers appropriate tools to design quiet brakes. There are two main categories of numerical methods that are used to study this problem: (1) transient dynamic analysis (Hu et al., 
1999; AbuBakar et al., 2006) and (2) complex eigenvalue analysis. Currently, the complex eigenvalue method is preferred and widely used (Liles, 1989; Lee et al., 1998; Blaschke et al., 2000; Bajer et al., 2003; AbuBakar et al., 2006; Liu et al., 2007; Mario et al., 2008; Dai et al., 2008) in predicting the squeal propensity of the brake system including damping and contact due to the quickness with which it can be analysed and its usefulness in providing design guidance by analysing with different operating parameters virtually.

Many researchers in their studies on the dynamics of brake system tried to reduce squeal by changing the factors associated with the brake squeal. For example (Liles, 1989) found that shorter pads, damping, softer disc and stiffer back plate could reduce squeal whilst in contrast, higher friction coefficient and wear of the friction material were prone to squeal. (Lee et al., 1998) reported that reducing back plate thickness led to less uniform of contact pressure distributions and consequently increasing the squeal propensity. (Hu et al., 1999) based on the DOE analysis found that the optimal design was the one that used the original finger length, the vertical slot, the chamfer pad, the $28 \mathrm{~mm}$ thickness of disc, and the $10 \mathrm{~mm}$ thickness of friction material. (Brooks et al., 1993) found that by shifting the pistons away from the leading edge of the pads the system could destabilise. They also reported that the predicted unstable system was due to the coupling of translational and rotational modes of the disc particularly at high values of pad stiffness. From the sensitivity studies, they suggested that the effective half length of the pad, the piston masses, the effective mass, inertia and grounding stiffness of the disc and the second circuit actuation stiffness also have potential on the disc brake instability. (Shin et al., 2002) have shown that the damping of the pad and the disc were important in reducing instability. Their analysis also has shown and confirmed that increasing damping of either the disc or the pad alone could potentially destabilise the system. (Liu et al., 2007) found that the squeal can be reduced by decreasing the friction coefficient, increasing the stiffness of the disc, using damping material on the back of the pads and modifying the shape of the brake pads. (Dai et al., 2008) have shown that the design of the pads with a radial chamfer possesses the least number of unstable modes, which implies lesser tendency towards squeal.

In the present study, an investigation of disc brake squeal is done by performing complex eigenvalue analysis using finite element software ABAQUS /standard. A positive real part of a complex eigenvalue is being seen as an indication of instability. Though the FE simulations can provide guidance, it will rather be trial-and-error approach to arrive at an optimal configuration and also one may need to run many number of computationally intensive analyses to formulate the 'input-out' relationships for possible prediction. Hence, in the present investigation, a novel approach is proposed by integrating the complex eigenvalue FE analyses with structured DOE. The proposed approach is aimed towards prediction of optimal pad design through the various factors of the brake pad geometrical construction.

The paper is organised as follows, it presents a detailed literature survey in this field in the recent period. From the literature survey the main objectives were formed. Methodology to develop FE model of the disc brake is presented and it was subsequently validated using experimental modal analysis. The CEA approach is presented in order to predict brake squeal. Then DOE approach for soft computing is presented. Also a methodology to test the adequacy of the developed statistical model is discussed.

\section{Finite element model and component correlation}

A disc brake system consists of a disc that rotates about the axis of a wheel, a caliper-piston assembly where the piston slides inside the caliper that is mounted to the vehicle suspension system, and a pair of brake pads. When hydraulic pressure is applied, the piston is pushed forward to press the inner pad against the disc and simultaneously the outer pad is pressed by the caliper against the disc. Figure 1 (a) shows the finite element model of the car front brake under consideration, built using the ABAQUS finite element software package. The brake model used in this study is a simplified model consisting of the two main components contributing to squeal: the disc and the pad (Figure 1(b)).

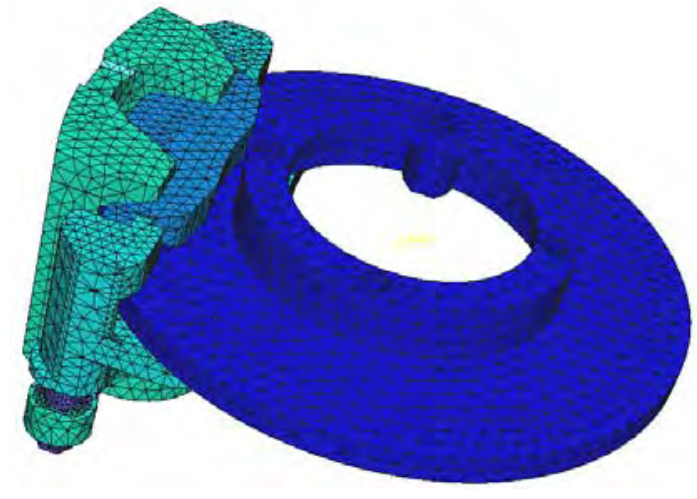

(a)

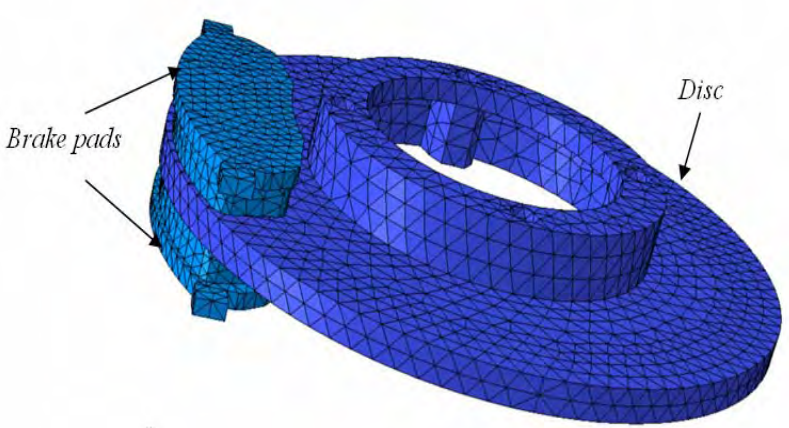

(b)

Figure 1. Finite element models of a (a) realistic (b) simplified disc brake model 
A simplified model was used in this study for the following reasons:

1. For brake squeal analysis, the most important source of nonlinearity is the frictional sliding contact between the disc and the pads.

2. The simulation includes geometry simplifications to reduce CPU time, allowing far more configurations to be computed.

The disc is made of cast iron. The pair of brake pads, which consist of friction material and back plates, are pressed against the disc in order to generate a friction torque to slow the disc rotation. The friction material is made of an organic friction material and the back plates are made of steel. The FE mesh is generated using 19,000 solid elements. The friction contact interactions are defined between both sides of the disc and the friction material of the pads. A constant friction coefficient and a constant angular velocity of the disc are used for simulation purposes. Figure 2 presents the constraints and loadings for the pads and disc assembly. The disc is completely fixed at the four counter-bolt holes and the ears of the pads are constrained to allow only axial movements. The caliper-piston assembly is not defined in the simplified model of the disc brake system, hence the hydraulic pressure is directly applied to the back plates at the contact regions between the inner pad and the piston and between the outer pad and the caliper, and it is assumed that an equal magnitude of force acts on each pad.
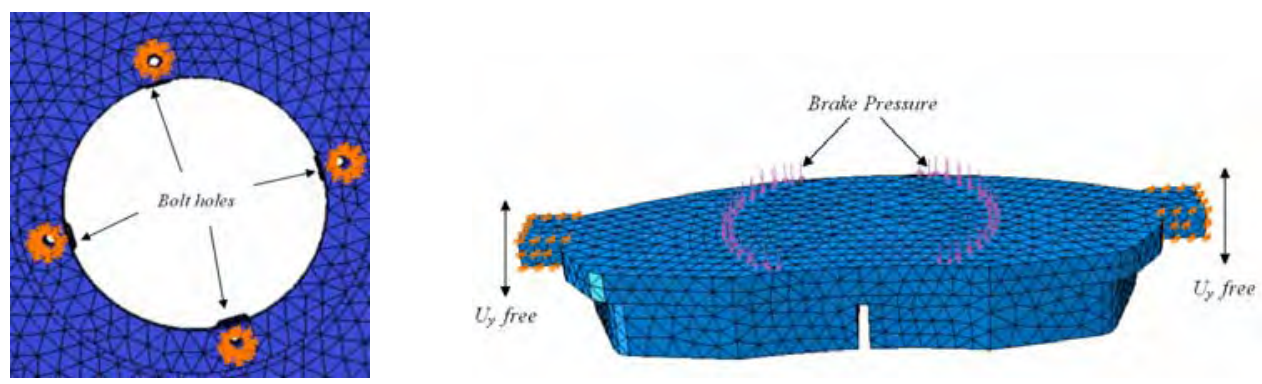

Figure 2. Constraints and loading of the simplified brake system

For the purpose of validation, the main brake components, Frequency Response Functions (FRF's) were measured at free-free boundary conditions by exciting each component with a small impact hammer with sensitivity of $10 \mathrm{mV} / \mathrm{N}$ and a hard tip. The acceleration response was measured with a light small accelerometer with sensitivity of $10 \mathrm{mV} / \mathrm{g}$ through Dynamic Signal Analyzer type DEWE-41-T-DSA. FRF measurements were recorded for each component using SISO configurations. Then, the FRF's were processed using DEWE FRF software in order to identify the modal parameters, namely; resonance frequencies, modal shapes and damping values. Figure 3 shows the experimental modal test components.

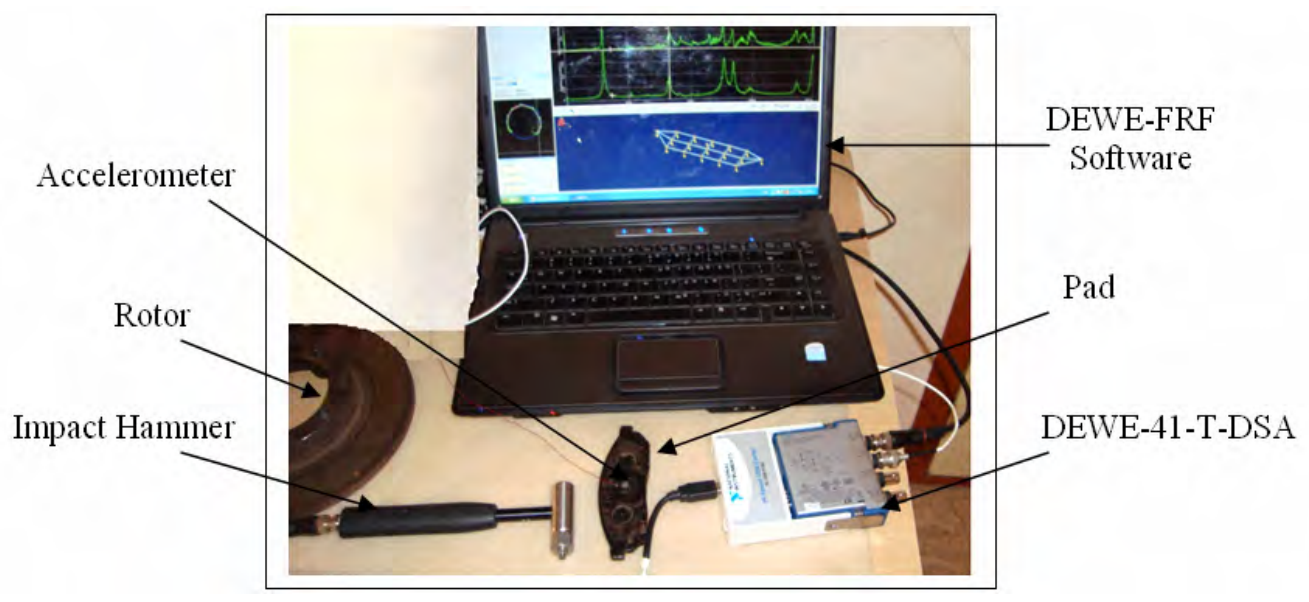

Figure 3. Experimental Modal Analysis Components

The frequencies measured on the disc and calculated by the simulated model for modes with free-free boundary conditions are shown in table 1. It can be observed that the measured and simulated frequencies are in good agreement. Figure 4 shows the mode shapes of rotor with nodal diameters. In a similar way, the parameters for the pads are estimated based on the measured data indicated in Table 2. The measured and simulated frequencies are in good agreement. Figure 5 shows the mode shapes of the pad. 
Table 1. Modal results of the rotor at free-free boundary conditions

\begin{tabular}{|c|c|c|c|}
\hline Mode shape & $\begin{array}{c}\text { Experimental } \\
\text { Frequency }(\mathrm{Hz})\end{array}$ & $\begin{array}{c}\text { FEA } \\
\text { Frequency(Hz) }\end{array}$ & Differences (\%) \\
\hline $2^{\text {nd }}$ bending & 1220 & 1303 & 6.8 \\
\hline $3^{\text {rd }}$ bending & 2551 & 2636 & 3.3 \\
\hline $4^{\text {th }}$ bending & 4003 & 4108 & 2.6 \\
\hline $5^{\text {th }}$ bending & 5774 & 5591 & -3.1 \\
\hline $6^{\text {th }}$ bending & 7873 & 7790 & -1 \\
\hline $7^{\text {th }}$ bending & 9008 & 9209 & 2.2 \\
\hline
\end{tabular}

Table 2. Modal results of the pad at free-free boundary conditions

\begin{tabular}{|c|c|c|c|}
\hline Mode shape & $\begin{array}{c}\text { Experimental } \\
\text { Frequency (Hz) }\end{array}$ & $\begin{array}{c}\text { FEA } \\
\text { Frequency(Hz) }\end{array}$ & Differences (\%) \\
\hline $1^{\text {st }}$ bending & 3051 & 3231 & 5.8 \\
\hline $2^{\text {nd }}$ bending & 8459 & 8381 & -1 \\
\hline
\end{tabular}

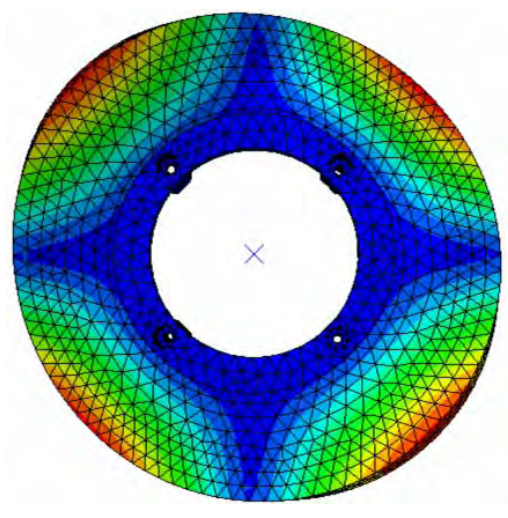

$2^{\text {nd }}$ Nodal Diameter Mode $(1303 \mathrm{~Hz})$

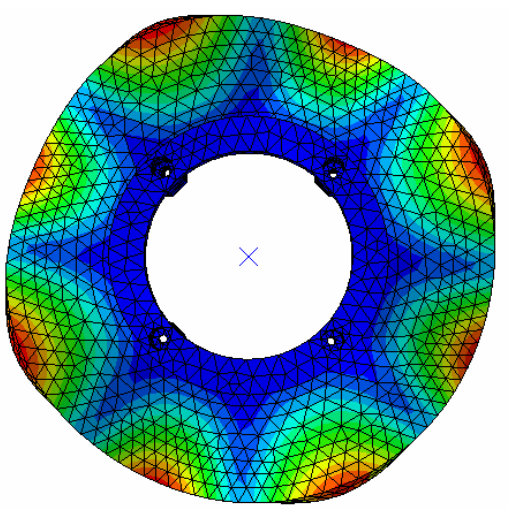

$4^{\text {th }}$ Nodal Diameter Mode $(4108 \mathrm{~Hz})$

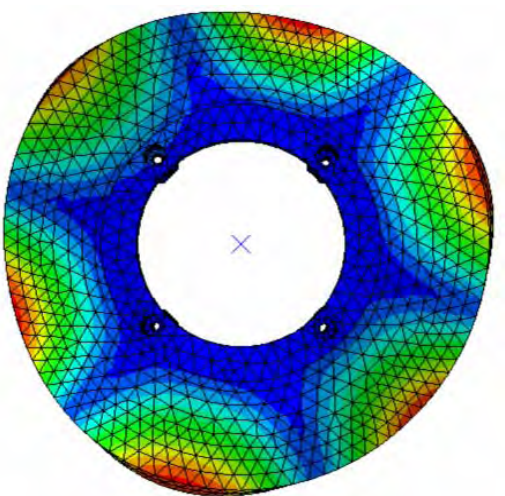

$3^{\text {rd }}$ Nodal Diameter Mode $(2636 \mathrm{~Hz})$

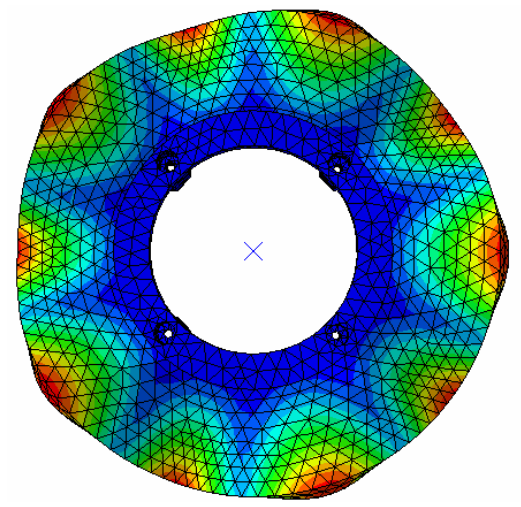

$5^{\text {th }}$ Nodal Diameter Mode $(5591 \mathrm{~Hz})$

Figure 4. Mode shapes of the rotor at free-free boundary conditions 


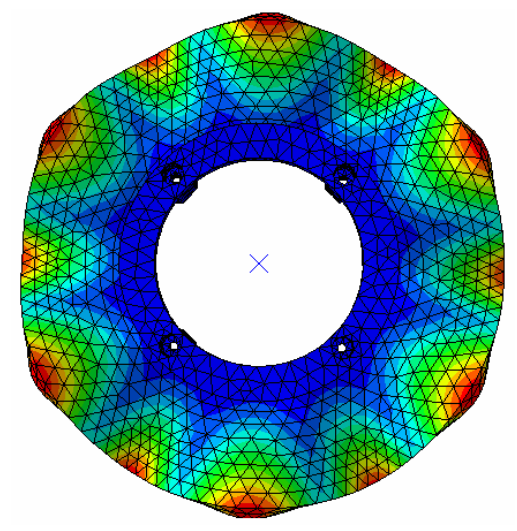

$6^{\text {th }}$ Nodal Diameter Mode $(7790 \mathrm{~Hz})$

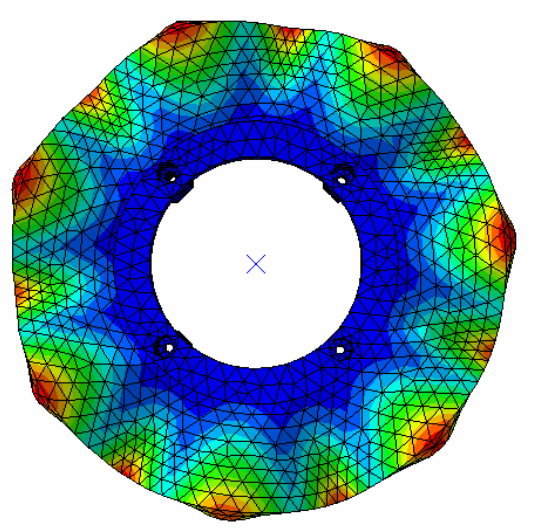

$7^{\text {th }}$ Nodal Diameter Mode $(9209 \mathrm{~Hz})$

Figure 4 (cont'd). Mode shapes of the rotor at free-free boundary conditions

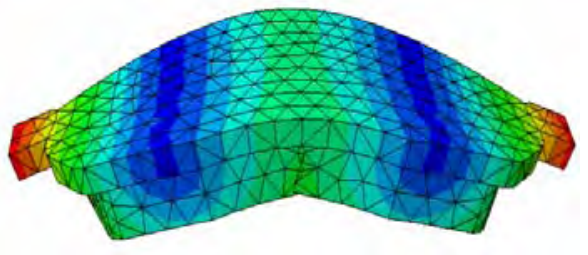

$1^{\text {st }}$ Bending Mode $(3231 \mathrm{~Hz})$

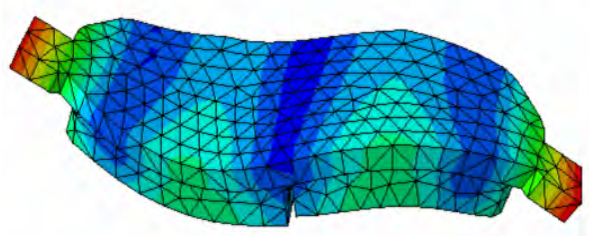

$2^{\text {nd }}$ Bending Mode $(8381 \mathrm{~Hz})$

Figure 5. Mode shapes of the pad at free-free boundary conditions.

\section{Complex eigenvalue analysis}

The complex eigenvalue analysis (CEA) has been widely used by researchers. It deals with computation of system eigenvalues which are prove to be complex valuated functions in the general case because friction causes the stiffness matrix to be asymmetric. The real and imaginary parts of the complex eigenvalues are, respectively, responsible for the stability and for the frequency of the corresponding modes. This method was first used on lumped models (Kinkaid et al., 2003; Ibrahim, 1994). Then, improvements in computer systems have made it possible to perform analyses on finite element (FE) models (Liles, 1989; Lee et al., 1998; Blaschke et al., 2000; Bajer et al., 2003; AbuBakar et al., 2006; Liu et al., 2007; Mario et al., 2008; Dai et al., 2008).

In order to perform the complex eigenvalue analysis using ABAQUS (Bajer et al, 2003), four main steps are required as follows: (1) nonlinear static analysis for the application of brake pressure; (2) nonlinear static analysis to impose a rotational velocity on the disc; (3) normal mode analysis to extract the natural frequency to find the projection subspace; and (4) complex eigenvalue analysis to incorporate the effect of friction coupling.

The governing equation of the system is:

$$
M u^{\prime \prime}+C u^{\prime}+K u=0
$$

Where M, C and $\mathrm{K}$ are respectively the mass, damping and stiffness matrices, and $\mathrm{u}$ is the displacement vector. Because of friction, the stiffness matrix has specific properties:

$$
K=K_{S}+\mu K_{F}
$$

Where $K_{S}$ is the structural stiffness matrix, $K_{F}$ the asymmetrical friction induced stiffness matrix and $\mu$ the friction coefficient. The governing equation can be rewritten as:

$$
\left(\lambda^{2} M+\lambda C+K\right) \phi=0
$$


Where, $\lambda$ is the eigenvalue and $\phi$ is the corresponding eigenvector. Both eigenvalues and eigenvectors may be complex. In order to solve the complex eigenproblem, this system is symmetrized by ignoring the damping matrix $\mathrm{C}$ and the asymmetric contributions to the stiffness matrix $\mathrm{K}$. Then this symmetric eigenvalue problem is solved to find the projection subspace. The $\mathrm{N}$ eigenvectors obtained from the symmetric eigenvalue problem are expressed in a matrix as $\left[\phi_{1}, \phi_{2}, \ldots \ldots . . . \phi_{N}\right]$. Next, the original matrices are projected onto the subspace of $\mathrm{N}$ eigenvectors

$$
\begin{aligned}
M^{*} & =\left[\phi_{1}, \phi_{2}, \ldots \ldots \ldots \phi_{N}\right]^{T} M\left[\phi_{1}, \phi_{2}, \ldots \ldots \ldots \phi_{N}\right], \\
C^{*} & =\left[\phi_{1}, \phi_{2}, \ldots \ldots \ldots \phi_{N}\right]^{T} C\left[\phi_{1}, \phi_{2}, \ldots \ldots \ldots \phi_{N}\right],
\end{aligned}
$$

and

$$
K^{*}=\left[\phi_{1}, \phi_{2}, \ldots \ldots \ldots \phi_{N}\right]^{T} K\left[\phi_{1}, \phi_{2}, \ldots \ldots \ldots \phi_{N}\right]
$$

Then the projected complex eigenproblem becomes

$$
\left(\lambda^{2} M^{*}+\lambda C^{*}+K^{*}\right) \phi^{*}=0
$$

Finally, the complex eigenvectors of the original system can be obtained by

$$
\phi^{k}=\left[\phi_{1}, \phi_{2}, \ldots \ldots \ldots \phi_{N}\right] \phi^{* k}
$$

Detailed description of the formulation and the algorithm are presented by Sinou et al. (2003). The eigenvalues and the eigenvectors of Eq. (3) may be complex, consisting of both a real and imaginary part. For under damped systems the eigenvalues always occur in complex conjugate pairs. For a particular mode the eigenvalue pair is

$$
\lambda_{i 1,2}=\alpha_{i} \pm i \omega_{i}
$$

Where, $\alpha_{i}$ and $\omega_{i}$ are the damping coefficient (the real part) and damped natural frequency (the imaginary part) describing damped sinusoidal motion. The motion for each mode can be described in terms of the complex conjugate eigenvalue and eigenvector. A positive damping coefficient causes the amplitude of oscillations to increase with time. Therefore the system is not stable when the damping coefficient is positive. By examining the real part of the system eigenvalues the modes that are unstable and likely to produce squeal are revealed. An extra term, damping ratio, is defined as $-2 \alpha /|\omega|$. If the damping ratio is negative, the system becomes unstable, and vice versa.

\subsection{Complex eigenvalue analysis (CEA) results}

Since friction is the main cause of instability, which causes the stiffness matrix in Eq. (3) to be asymmetric, complex eigenvalue analysis has been undertaken to assess the brake stability as the friction coefficient values. It was observed that high values for this parameter tend to facilitate two modes merging to form an unstable complex mode. In addition, an increase in the friction coefficient leads to an increase in the unstable frequency. Figure 6 shows the results of a complex eigenvalue analysis with variation of the friction coefficient $(\mu)$ between 0.2 and 0.6. As predicted in the complex eigenvalue analysis, as the friction coefficient further increases, real parts of eigenvalues, the values that can be used to gauge the degree of instability of a complex mode, increase further, as well, and more unstable modes may emerge. This is because the higher coefficient of friction causes the variable frictional forces to be higher resulting in the tendency to excite greater number of unstable modes. In the past, a friction coefficient of 0.35 was typical. However, brake compounds today possess coefficient of friction that is 0.45 or higher, which increases the likelihood of squeal. This poses a greater challenge for brake designer to develop a quiet brake system.

In an earlier work (Nouby et al., 2009), an attempt was made using parametric study to reduce squeal at $12 \mathrm{kHz}$. Based on the earlier study, a decision was taken to understand the effects of influencing variables of squeal at $6.2 \mathrm{kHz}$ using DOE. 


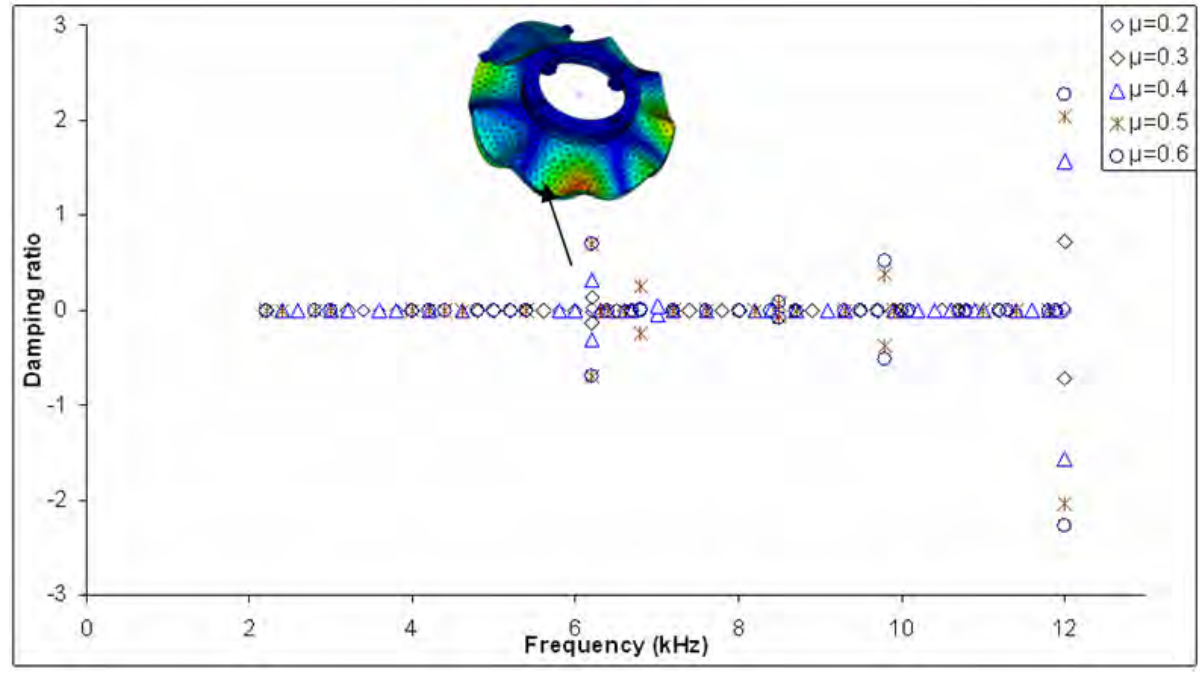

Figure 6. Results of CEA with variation of $\mu$, and unstable mode at interested Frequency $(6.2 \mathrm{kHz})$

\section{Methodology}

Human made products or processes can be treated like a system, if it produces a set of responses for a given set of inputs. Disc brake system can also be treated like a system as shown in Figure 7. Some systems like disc brake system produce unwanted outputs namely squeal for a set of inputs parameters. The present study was aimed at establishing the input-output relationships for prediction of brake squeal.

Disc brake system has numerous variables. In order to arrive at the most influential variables and its effects a two phase strategies were proposed. In the first phase, initial screening with various variables was taken up. Fractional factorial design (FFD) of experiments was conducted to identify the most influential variables. Subsequently, in the second phase, central composite design (CCD) based Response surface methodology (RSM) was deployed to develop a non-linear model for prediction of disk brake squeal.

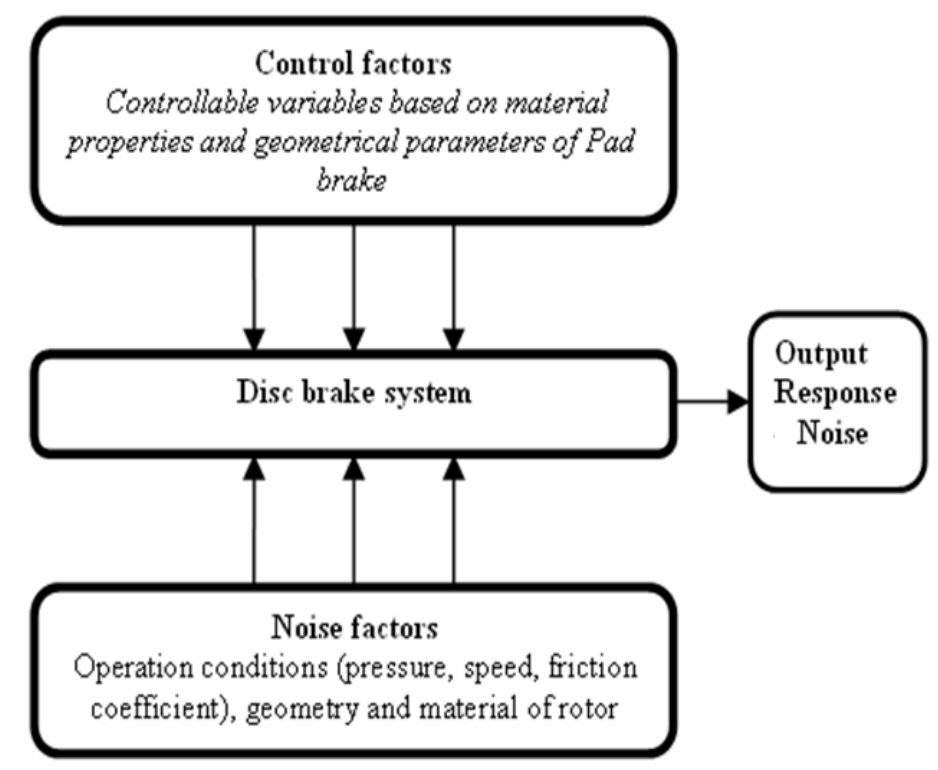

Figure 7. Disc brake squeal system

\subsection{First phase: screening FFD of experiments}

If any experiment involves the study of the effects of two or more factors, then factorial designs are more efficient than onefactor-at-a-time experiments. Furthermore, a factorial design is necessary when interactions may be present to avoid misleading 
conclusions (Montgomery, 2005). Hence, in the first phase, an $\mathrm{L}_{8}$ FFD array was used for screening. Parameters used for the initial screening and its levels are indicated in Table 3. Detailed discussions on the selection of parameters are included in section 4.3.

Table 3. Initial screening parameters and their levels

\begin{tabular}{|c|l|c|c|c|}
\hline \multicolumn{2}{|c|}{ Factor } & & \multicolumn{2}{c|}{ Level } \\
\hline Coded & Uncoded & Units & Low & High \\
\hline A & Back plate Young’s modulus & GPa & 190 & 230 \\
\hline B & Back plate thickness & $\mathrm{mm}$ & 4 & 6 \\
\hline C & Friction material Chamfer & $\mathrm{mm}$ & 5 & 9 \\
\hline D & Slot width & $\mathrm{mm}$ & 1 & 3 \\
\hline E & Distance between slots & $\mathrm{mm}$ & 30 & 50 \\
\hline F & Slot Angle & Deg. & 5 & 15 \\
\hline
\end{tabular}

\subsection{Second phase: $R S M-C C D$ of experiments}

CCD is one of the most important experimental designs used for optimizing parameters. CCD is nothing but $2^{\mathrm{k}}$ factorial design augmented with centre points and axial points. CCD is far more efficient than running $3^{\mathrm{k}}$ factorial design with quantitative factors (Montgomery, 2005). Hence CCD approach was selected for the present study. In light of the first phase, four variables out of the six variables were selected for the second phase.

The CCD of experiments for four factors consists of the following:

1. Full factorial design for the four factors $\left(2^{4}\right)$

2. 1 centre point runs

3. 8 Axial points with $\alpha$ value 2 . The $\alpha$ value is nothing but the distance between centre point and some additional axial points to fit a non-linear curve.

A second order polynomial equation was developed to study the effects of the variables on the negative damping ratio. The equation is of the general form

$$
Y=A_{0}+\sum_{i=1}^{k} A i X i+\sum_{i<j} \sum A_{i j} X_{i} X_{j}+\sum_{i=1}^{k} A_{i i} X_{i}{ }^{2}
$$

The above equation contains linear terms, squared terms and interaction terms. Equation (8) can be rewritten in matrix form as

$$
Y=A_{0}+X^{T} b+X^{T} C X
$$

Where $\mathrm{X}^{\mathrm{T}}=\left(\mathrm{X}_{1}, \mathrm{X}_{2}, \ldots, \mathrm{X}_{\mathrm{k}}\right), \mathrm{b}=\left(\mathrm{A}_{1}, \mathrm{~A}_{2,} \ldots, \mathrm{A}_{\mathrm{k}}\right)$ and $\mathrm{C}$ is the $\mathrm{k} \mathrm{x}$ k symmetric matrix $(3)$

$$
\mathbf{C}=\left[\begin{array}{ccccc}
A_{11} & \frac{1}{2} A_{12} & \cdot & \cdot & \frac{1}{2} A_{1 k} \\
\frac{1}{2} A_{12} & A_{22} & \cdot & \cdot & \frac{1}{2} A_{2 k} \\
\cdot & \cdot & \cdot & \cdot & \cdot \\
\cdot & \cdot & \cdot & \cdot & \cdot \\
\frac{1}{2} A_{1 k} & \frac{1}{2} A_{2 k} & & & A_{k k}
\end{array}\right]
$$

Equation (9) will be differentiated with respect to $\mathrm{X}$ and equated to zero in order to obtain different coefficients of the secondorder polynomial equation. Minitab software was used for calculation of coefficients and for analysis.

\subsection{Control variables/factors}

This work was directed to study and possibly prevent certain unstable modes which causes squeal at frequency $6.2 \mathrm{kHz}$. Disc brake squeal is dependent upon numerous factors based on geometry, material characteristics and operating conditions. The factors can be broadly classified into:

1. Fixed factors

2. Variable factors 


\subsubsection{Setting up of fixed processing factors}

Squeal in brake system is relatively complex. Inputs (both fixed and variable factors) affect the output. The disk brake system in abstract form is shown in Figure 7. For the purpose of the present work, factors like the hydraulic pressure, rotational velocity of the disc, friction coefficient at the contact interactions between the pads and the disc and the stiffness of the disc and friction material property of brake pads are fixed at specific values.

\subsubsection{Selection of controllable processing factors}

Based on the literature survey and discussions with service engineers, six controllable factors were taken up for initial screening. They are listed in the Table 3.

\subsubsection{Variation of Young's modulus of back plate}

The Young's modulus is a critical variable and various researchers have attempted (Liu et al., 2007; Nouby et al., 2009) variation in the Young's modulus value. In this study, this factor was varied between 190 and 230 GPa.

\subsubsection{Variation of back plates thickness.}

Commonly used back plate thickness is $5 \mathrm{~mm}$ for the type of the brake system under study. In order to understand the effects and arrive at back plate thickness, thickness was varied between 4 and $6 \mathrm{~mm}$.

\subsubsection{Variation of the chamfer size}

The original pads for this commercial brake did not contain any chamfer. During the literature survey, this parameter was found to contribute to a certain extent to the squeal (Dai et al., 2008; Dunlap et al., 1999). Hence an angle of 45 was provided on both sides of the friction material and the size of chamfer was varied between $5 \mathrm{~mm}$ and $9 \mathrm{~mm}$.

\subsubsection{Slots configurations on the pad}

In this study, a double slot configuration was attempted Figure 8. This configuration has three variables. They are the slot width, slot angle or orientation and the distance between the two slots. The slot width was varied between $1 \mathrm{~mm}$ and $3 \mathrm{~mm}$. the slot angle/orientation was altered between 5 and 15 degrees, as shown in Figure 8, and distance between the slots was varied between 30 and $50 \mathrm{~mm}$.
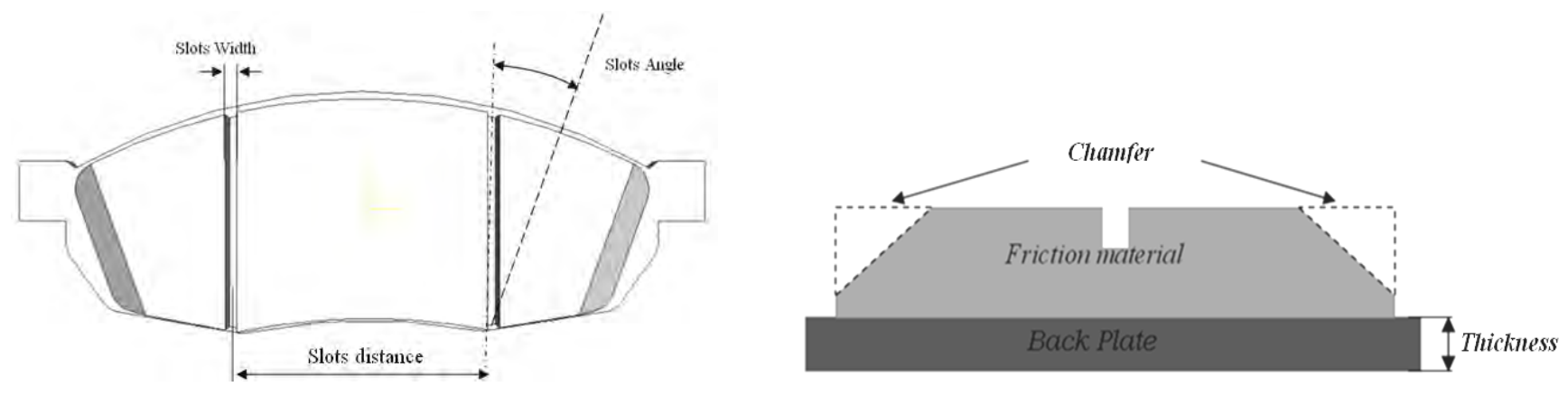

Figure 8. Various factors of the brake pad geometry

\section{Experimental results and analysis}

This section discusses about the three phases of experiments, its results, developed mathematical models of the system and its adequacy.

\subsection{First phase - initial screening FFD experiments}

A total number of eight trials were conducted and the negative damping ratio was measured for each case. The recorded negative damping ratio along with FFD array is tabulated in Table 4. Pareto chart of the effects is plotted to determine the magnitude and the importance of the effects Figure 9. It displays the absolute values of the effects of each factor.

Main effects plot shown in Figure 10 also confirms the contributions of the factors considered. 
Table 4. $\mathrm{L}_{8}$ Initial FFD array and measured negative damping ratio (NDR)

\begin{tabular}{|c|l|l|l|l|l|l|l|}
\hline Runs & A & B & C & D & E & F & NDR \\
\hline 1 & 190 & 4 & 5 & 3 & 50 & 15 & 0.001 \\
\hline 2 & 230 & 4 & 5 & 1 & 30 & 15 & 0.53 \\
\hline 3 & 190 & 6 & 5 & 1 & 50 & 5 & 0.52 \\
\hline 4 & 230 & 6 & 5 & 3 & 30 & 5 & 1.11 \\
\hline 5 & 190 & 4 & 9 & 3 & 30 & 5 & 4.34 \\
\hline 6 & 230 & 4 & 9 & 1 & 50 & 5 & 0.01 \\
\hline 7 & 190 & 6 & 9 & 1 & 30 & 15 & 2.66 \\
\hline 8 & 230 & 6 & 9 & 3 & 50 & 15 & 0.03 \\
\hline
\end{tabular}

\subsection{Second phase - RSM -CCD of experiments}

In light of the screening experiments, a decision was taken to study the effects of the top four factors, namely; Young's modulus of the pad back plate, chamfer, and slot angle and distance between two slots. The variables and their levels are listed in Table 5.

Table 5. Coded levels of variable and actual values for CCD

\begin{tabular}{|c|l|c|c|c|}
\hline \multicolumn{2}{|c|}{ Factor } & & \multicolumn{2}{c|}{ Level } \\
\hline Coded & Uncoded & Units & Low & High \\
\hline A & Back plate Young's modulus & GPa & 190 & 230 \\
\hline C & Friction material Chamfer & $\mathrm{mm}$ & 5 & 9 \\
\hline E & Distance between slots & $\mathrm{mm}$ & 30 & 50 \\
\hline F & Angle of slots & Deg. & 5 & 15 \\
\hline
\end{tabular}

Pareto Chart of the Effects

(response is damping ratio, Alpha $=.05$ )

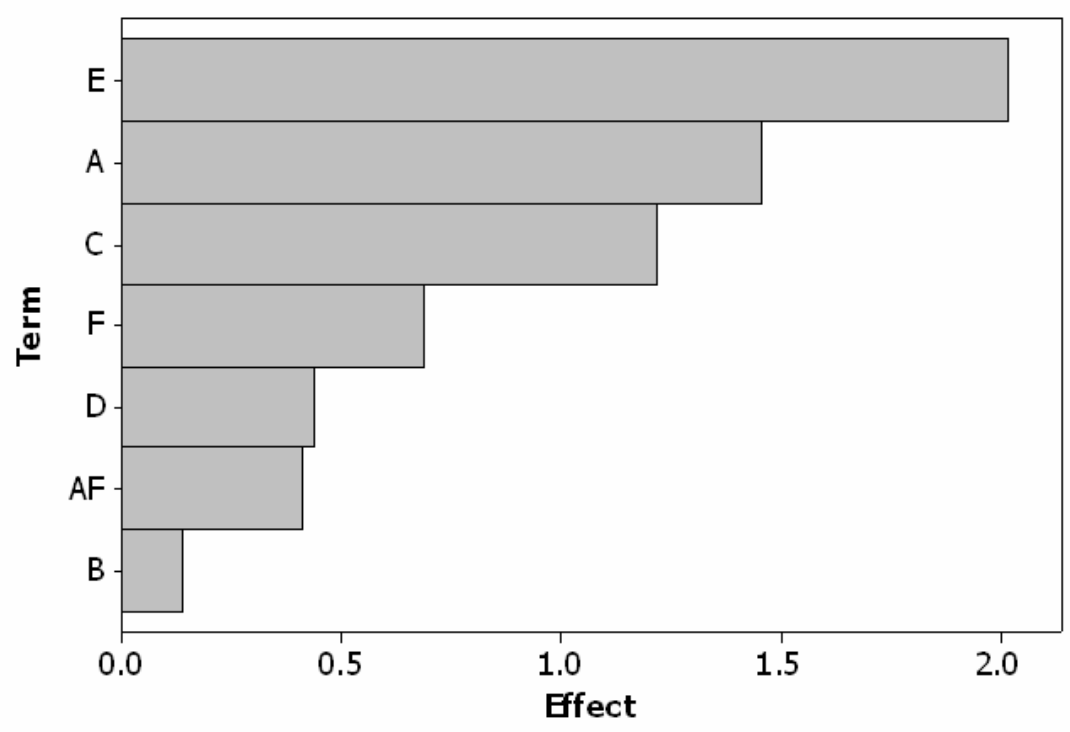

\begin{tabular}{|ll|}
\hline Factor & Name \\
A & stiffness \\
B & thickness \\
C & chamfer \\
D & width \\
E & dist bet slots \\
F & angle \\
\hline
\end{tabular}

Figure 9. Pareto chart of effects of initial screening. 


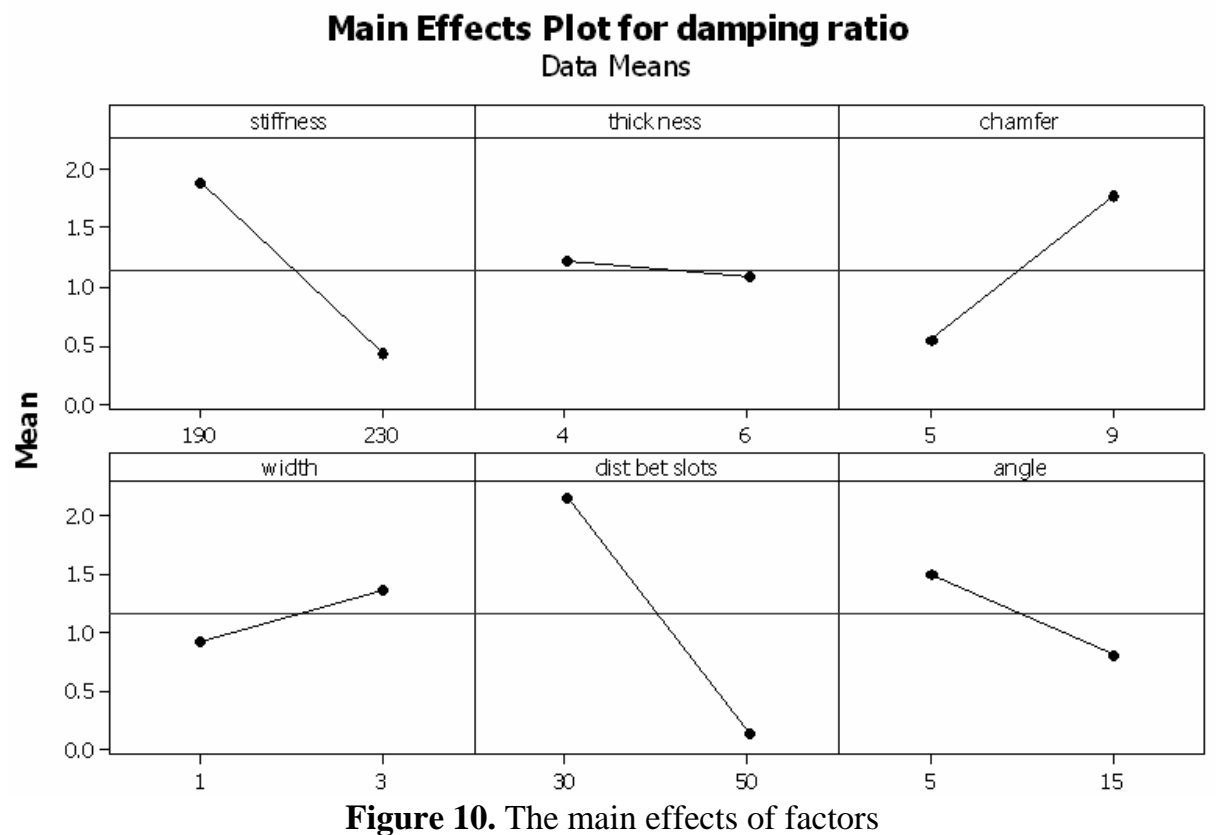

A total number of twenty five trials were conducted and a set of data was collected as per the structure of CCD of experiments. Table 6 lists the experimental results.

Table 6. Experimental results of CCD

\begin{tabular}{|l|l|l|l|l|l|}
\hline Runs & A & C & E & F & NDR \\
\hline 1 & 190 & 5 & 30 & 5 & 3.53 \\
\hline 2 & 230 & 5 & 30 & 5 & 0.57 \\
\hline 3 & 190 & 9 & 30 & 5 & 3.55 \\
\hline 4 & 230 & 9 & 30 & 5 & 0.09 \\
\hline 5 & 190 & 5 & 50 & 5 & 1.89 \\
\hline 6 & 230 & 5 & 50 & 5 & 0.12 \\
\hline 7 & 190 & 9 & 50 & 5 & 0.12 \\
\hline 8 & 230 & 9 & 50 & 5 & 0.01 \\
\hline 9 & 190 & 5 & 30 & 15 & 3.21 \\
\hline 10 & 230 & 5 & 30 & 15 & 0.29 \\
\hline 11 & 190 & 9 & 30 & 15 & 2.74 \\
\hline 12 & 230 & 9 & 30 & 15 & 0.01 \\
\hline 13 & 190 & 5 & 50 & 15 & 0.37 \\
\hline 14 & 230 & 5 & 50 & 15 & 0.17 \\
\hline 15 & 190 & 9 & 50 & 15 & 1.10 \\
\hline 16 & 230 & 9 & 50 & 15 & 0.19 \\
\hline 17 & 170 & 7 & 40 & 10 & 3.90 \\
\hline 18 & 250 & 7 & 40 & 10 & 0.01 \\
\hline 19 & 210 & 3 & 40 & 10 & 0.84 \\
\hline 20 & 210 & 11 & 40 & 10 & 0.10 \\
\hline 21 & 210 & 7 & 20 & 10 & 2.67 \\
\hline 22 & 210 & 7 & 60 & 10 & 0.05 \\
\hline 23 & 210 & 7 & 40 & 0 & 1.52 \\
\hline 24 & 210 & 7 & 40 & 20 & 0.01 \\
\hline 25 & 210 & 7 & 40 & 10 & 0.38 \\
\hline & & & & \\
\hline
\end{tabular}


A significance test was conducted to examine the effects of different process parameters and their interaction terms on the negative damping ratio. Table 7 shows the estimated coefficients for the negative damping ratio.

Table 7. Estimated regression coefficients for the negative damping ratio

\begin{tabular}{|l|l|l|l|c|}
\hline \multicolumn{1}{|c|}{ Term } & \multicolumn{1}{c|}{ Coeff } & SE Coeff & \multicolumn{1}{c|}{ T } & P \\
\hline Constant & 0.380000 & 0.28501 & 1.3330 & 0.2090 \\
\hline A & -0.951667 & 0.08228 & -11.5670 & 0.0000 \\
\hline C & -0.159167 & 0.08228 & -1.9350 & 0.0790 \\
\hline E & -0.635833 & 0.08228 & -7.7280 & 0.0000 \\
\hline F & -0.200833 & 0.08228 & -2.4410 & 0.0330 \\
\hline A*A & 0.391250 & 0.09648 & 4.0550 & 0.0020 \\
\hline C $^{*}$ C & 0.020000 & 0.09648 & 0.2070 & 0.8400 \\
\hline E*E & 0.242500 & 0.09648 & 2.5140 & 0.0290 \\
\hline$F^{*} F$ & 0.093750 & 0.09648 & 0.9720 & 0.3520 \\
\hline A*C & 0.040000 & 0.10077 & 0.3970 & 0.6990 \\
\hline A*E & 0.567500 & 0.10077 & 5.6320 & 0.0000 \\
\hline A*F & 0.096250 & 0.10077 & 0.9550 & 0.3600 \\
\hline C*E & 0.005000 & 0.10077 & 0.0500 & 0.9610 \\
\hline C*F & 0.146250 & 0.10077 & 1.4510 & 0.1750 \\
\hline E*F & 0.073750 & 0.10077 & 0.7320 & 0.4800 \\
\hline
\end{tabular}

Different terms used in the Table 6 are as follows. The term 'coeff' stands for coefficients used in the regression equation for representing relationships between the negative damping ratio and the various factors. The term 'SE coeff' stands for the standard error for the estimated coefficients, which measures the precision of the estimates. The smaller values of standard error indicate that better precision of coefficient estimates. The term ' $T$ ' values are calculated as the ratio of corresponding value under coefficient and standard error. The ' $\mathrm{T}$ value' of the independent variable can be used to test whether the predictor significantly predicts the response. The ' $\mathrm{P}$ ' value determines the appropriateness of rejecting the null hypothesis in a hypothesis test. The Pvalues range from 0 to 1 . The smaller the P-value, the smaller the probability that rejecting the null hypothesis is a mistake. The Pvalues less than 0.05 indicate that the corresponding model terms are significant. In this present study, $\mathrm{A}, \mathrm{E}, \mathrm{F} \mathrm{A}^{2}, \mathrm{E}^{2}$ and $\mathrm{AE}$ are significant model terms to the response damping ratio. It can be observed that, though the term $\mathrm{F}$ is significant its square term is found to be insignificant. It indicates that, F's relationship could be linear in nature. Figure 11(a) to 11(f) show the 3D surface plots for the response - negative damping ratio $(\mathrm{Y})$.

The following observations can be made from the surface plots:

1. From the surface plot, Figure 11(a) it is found that increased Young's modulus (A) in combination with reduced angle of slot (F) decrease negative damping ratio.

2. It is observed Figure 11(b) that, as the distance between two slots are closer with increased Young's modulus reduces the negative damping ratio. Surface plot of A and E interaction confirms its significance on the output.

3. It is observed Figure 11(c) that, as the chamfer increases the negative damping ratio reduces on the other hand as the angle in combination with increasing chamfer causes the negative damping ratio to behave non-linearly. It is also noted from the surface plot the near significance of $\mathrm{C}$ and $\mathrm{F}$ interaction.

4. From Figure 11(d) it can be observed that increased chamfer value does not have significant interaction with increase in Young's modulus.

5. It is observed from the Figure 11(e) that, increase in the distance between slots reduces the negative damping ratio and the increase in the chamfer value does not have considerable effect in $\mathrm{C}$ and $\mathrm{E}$ interaction.

6. From the Figure 11(f) it is observed that increase in the distance between slots reduces the negative damping ratio and the change in the angle does not have much influence in $\mathrm{E}$ and $\mathrm{F}$ interaction. 


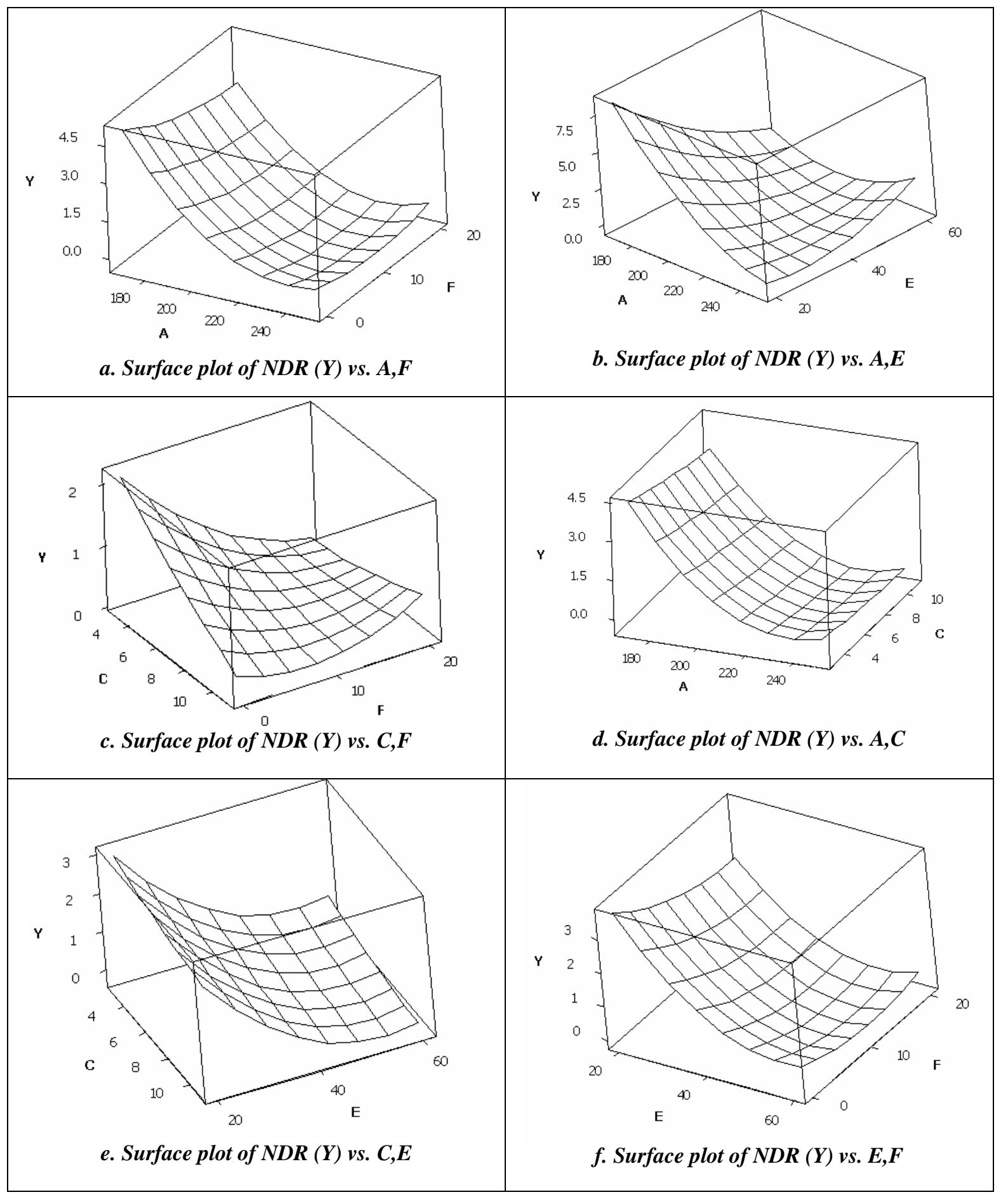

Figure 11. 3D Surface plots for the response- negative damping ratio (Y)

From the above observations, it may be concluded that squeal propensity decreases with higher back plate Young's modulus, higher distance between two slots and higher chamfer in both sides of friction material. ANOVA was performed to test the significance of the factors (Refer Table 8). 
Table 8. ANOVA for negative damping ratio

\begin{tabular}{|l|l|l|l|l|l|l|}
\hline Source & DF & Seq SS & Adj SS & Adj MS & F & P \\
\hline Regression & 14 & 42.40710 & 42.40710 & 3.02908 & 18.64 & 0.000 \\
\hline Linear & 4 & 33.01490 & 33.01490 & 8.25373 & 50.8 & 0.000 \\
\hline Square & 4 & 3.63580 & 3.63580 & 0.90895 & 5.59 & 0.010 \\
\hline Interaction & 6 & 5.75640 & 5.75640 & 0.95940 & 5.91 & 0.006 \\
\hline Residual Error & 11 & 1.78710 & 1.78710 & 0.16246 & & \\
\hline Lack-of-Fit & 10 & 1.78710 & 1.78710 & 0.17871 & & \\
\hline Pure Error & 1 & 0.00000 & 0.00000 & 0.00000 & & \\
\hline Total & 25 & 44.19420 & & & & \\
\hline
\end{tabular}

Different terms used in the Table-8 are as follows. The term 'DF' means degrees of freedom. The DF refers to the number of terms that will contribute to the error prediction. The term 'Seq SS' represents the sum of squares for each term, which measures the variability in the data contributed by the term. The term 'Adj SS' means adjusted sum of squares after removing insignificant terms from the model.

The Model F-value of 18.64 implies the model is significant. There is only a $0.01 \%$ chance that a "Model F-Value" this large could occur due to noise. Values of "Prob > F" less than 0.0500 indicate model terms are significant. In this case A, C, F, AE, A², and $\mathrm{E}^{2}$ are significant model terms. Values greater than 0.1000 indicate the model terms are not significant.

Figure 12 shows the normal probability plot of residuals. It shows that there is no abnormality in the methodology adopted $\left(\mathrm{R}^{2}=\right.$ 0.9596). The $\mathrm{R}^{2}$ analysis is tabulated in Table 9. The "Pred R-Squared" of 0.7671 is in reasonable agreement with the "Adj RSquared" of 0.9081. "Adeq Precision" measures the signal to noise ratio. Model's ratio of 13.476 indicates an adequate signal. The statistical analysis shows that, the developed non-linear model based on central composite design is statistically adequate and can be used to navigate the design space.

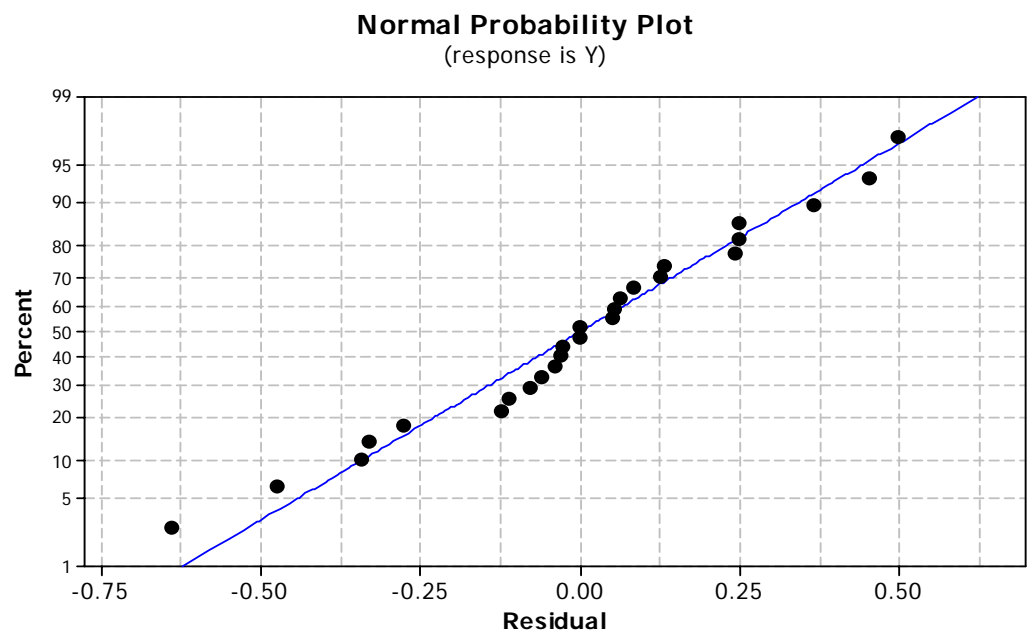

Figure 12. Normal probability plot for residuals

Table 9. $\mathrm{R}^{2}$ analysis

\begin{tabular}{|l|l|}
\hline Std. Dev. & 0.40 \\
\hline Mean & 1.07 \\
\hline C.V. $\%$ & 37.67 \\
\hline PRESS & 10.29 \\
\hline R-Squared & 0.9596 \\
\hline Adj R-Squared & 0.9081 \\
\hline Pred R-Squared & 0.7671 \\
\hline Adeq Precision & 13.476 \\
\hline
\end{tabular}


The response equation for negative damping ratio in coded form is given under:

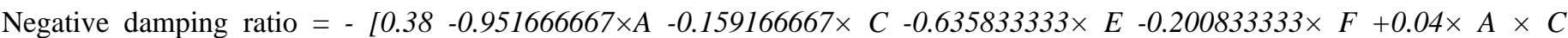
$+0.5675 \times A \times E+0.09625 \times A \times F+0.005 \times C \times E+0.14625 \times C \times F+0.07375 \times E \times F+0.39125 \times A \wedge 2+0.02 \times C \wedge 2+0.2425 \times$ $\left.E^{\wedge} 2+0.09375 \times F^{\wedge} 2\right]$

\subsection{Testing of model}

The model was statistically validated as explained above. Performance of the developed model was also tested on randomly generated 22 test runs. Table 10 gives the factor settings, predicted responses, measured negative damping ratio and percentage deviation for each run.

Table 10. Comparison between predicted versus actual simulation

\begin{tabular}{|c|l|l|l|l|l|l|l|}
\hline Test & A & C & E & F & Actual & Predicted & \% Deviation \\
\hline 1 & 200 & 6 & 45 & 7 & 0.750 & 0.853 & 13.69 \\
\hline 2 & 205 & 8 & 35 & 12 & 1.010 & 0.951 & 5.89 \\
\hline 3 & 210 & 8 & 45 & 9 & 0.065 & 0.071 & 9.68 \\
\hline 4 & 200 & 7 & 45 & 11 & 0.550 & 0.516 & 6.22 \\
\hline 5 & 195 & 8 & 40 & 7 & 1.210 & 1.378 & 13.88 \\
\hline 6 & 195 & 7 & 40 & 10 & 1.250 & 1.314 & 5.11 \\
\hline 7 & 220 & 6 & 40 & 10 & 0.068 & 0.077 & 12.59 \\
\hline 8 & 215 & 8 & 40 & 7 & 0.170 & 0.193 & 13.47 \\
\hline 9 & 225 & 7 & 35 & 7 & 0.170 & 0.185 & 8.89 \\
\hline 10 & 205 & 6 & 35 & 12 & 1.080 & 1.064 & 1.51 \\
\hline 11 & 205 & 6 & 40 & 7 & 0.940 & 0.945 & 0.48 \\
\hline 12 & 195 & 8 & 35 & 11 & 1.660 & 1.771 & 6.67 \\
\hline 13 & 200 & 6 & 35 & 7 & 1.750 & 1.819 & 3.94 \\
\hline 14 & 220 & 6 & 35 & 10 & 0.291 & 0.314 & 8.07 \\
\hline 15 & 200 & 8 & 45 & 10 & 0.442 & 0.471 & 6.52 \\
\hline 16 & 215 & 6 & 45 & 10 & 0.060 & 0.059 & 1.82 \\
\hline 17 & 195 & 6 & 45 & 8 & 1.140 & 1.081 & 5.20 \\
\hline 18 & 210 & 7 & 45 & 8 & 0.213 & 0.203 & 4.56 \\
\hline 19 & 195 & 6 & 40 & 13 & 1.223 & 1.239 & 1.35 \\
\hline 20 & 215 & 8 & 40 & 13 & 0.071 & 0.069 & 3.50 \\
\hline 21 & 195 & 7 & 35 & 9 & 1.964 & 1.971 & 0.35 \\
\hline 22 & 195 & 8 & 45 & 13 & 0.670 & 0.691 & 3.18 \\
\hline
\end{tabular}

$\%$ Deviation $=\mid[$ (actual value - predicted value $) /$ actual value $] \times 100$

Figure 13 shows the graphical presentation of predicted versus actual simulation. The best fit line plot (Figure 14) of the 22 points was found to be close to the ideal $\mathrm{Y}=\mathrm{X}$ line. Predicted responses show good agreement with actual results. Figure 15 shows the percentage deviation plot. The average absolute percentage deviation was found to be 6.2. Actual results varied between $-13.69 \%$ and $6.21 \%$ from predicted responses. This indicates that designed model space can be navigated for prediction. 


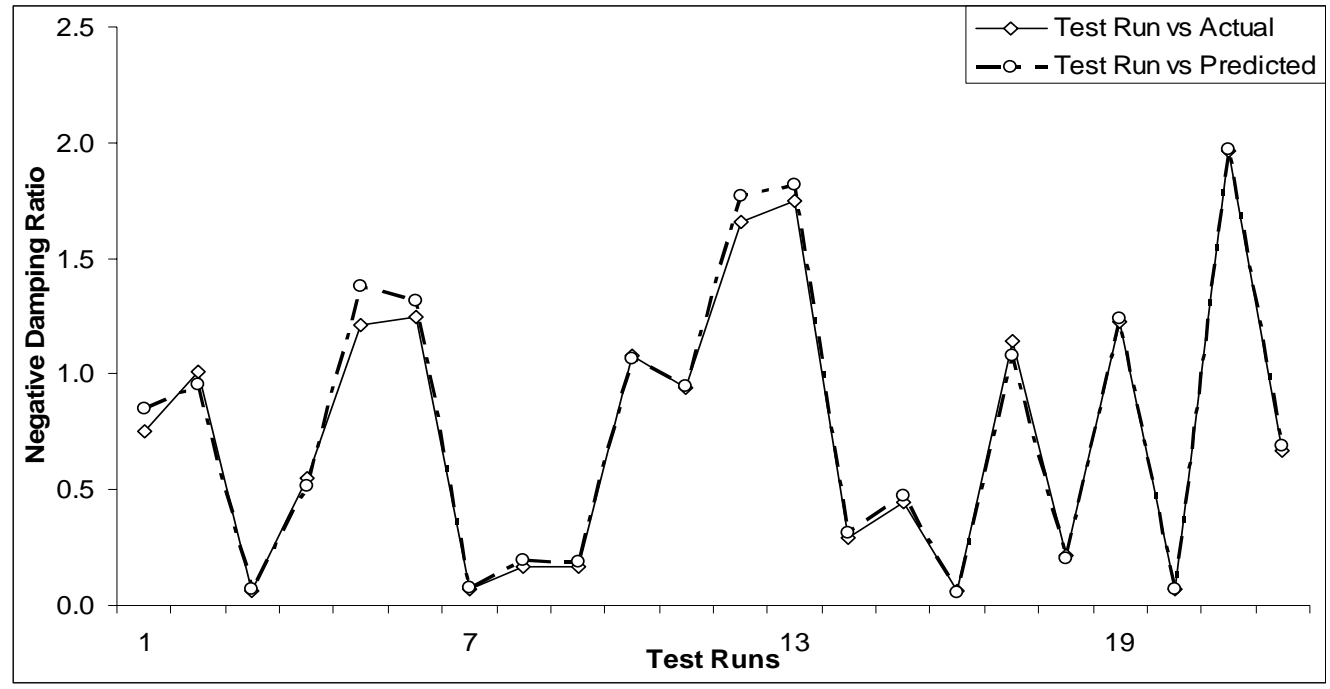

Figure 13. Predicted versus actual simulation

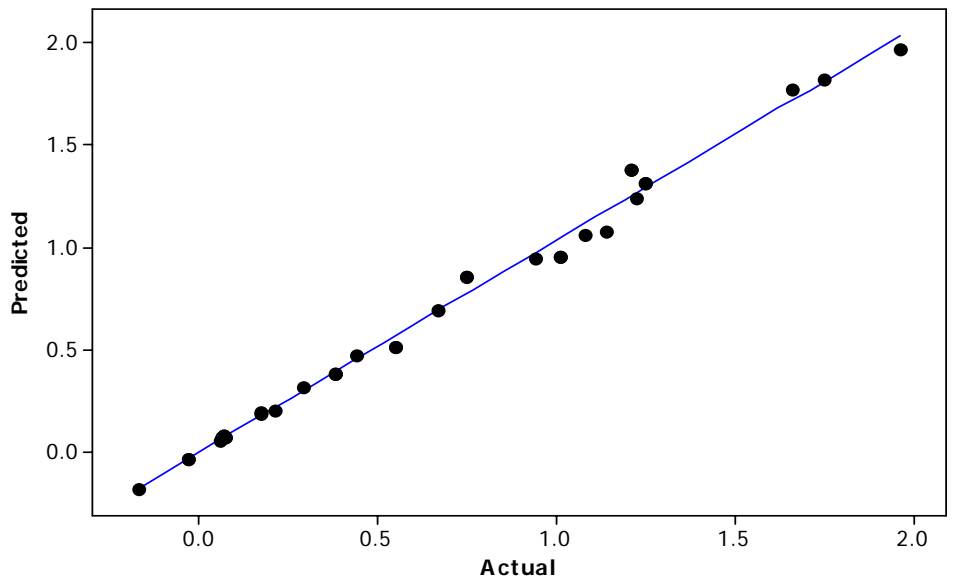

Figure 14. The best fit line plot

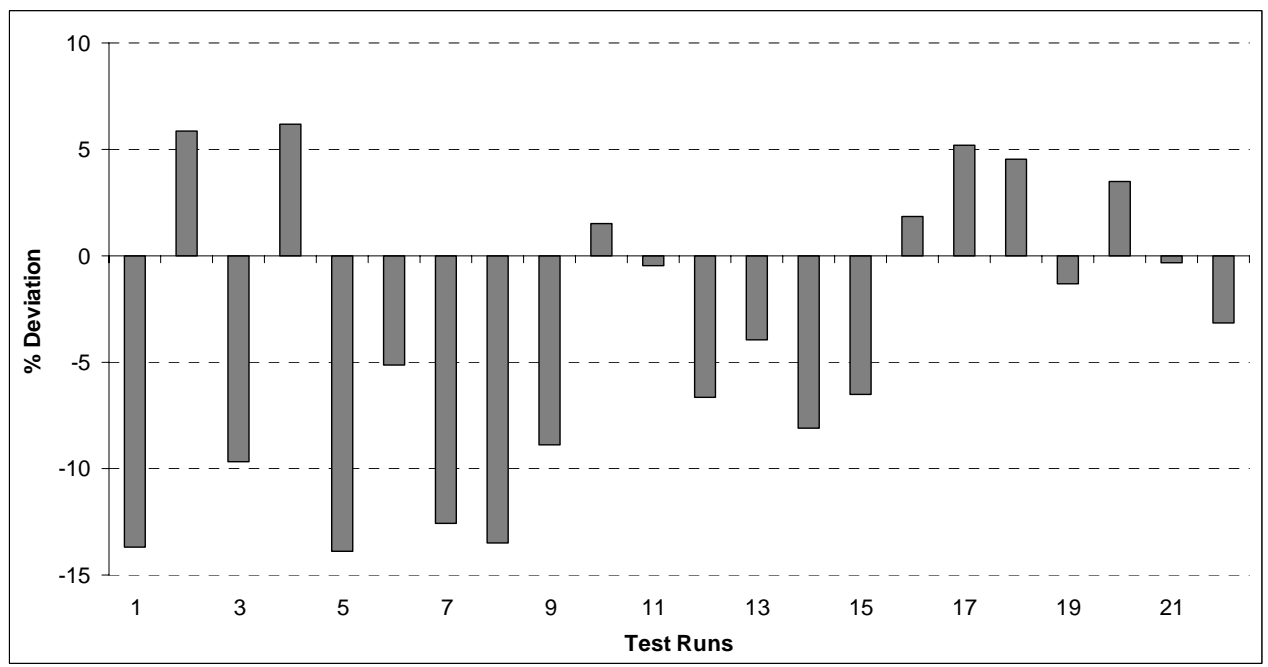

Figure 15. Percentage deviation of experimental results 


\section{Conclusion}

Non-linear model for the damping ratio based on Central composite design of experiments was successfully developed for prediction of brake squeal. To validate the model, randomly generated twenty two test cases were examined. Deviations between predicted and actual simulation results were found to be within $\pm 15 \%$. It shows reasonable agreement and also the adequacy of the developed model in prediction. Though these investigations are predominantly for the disc brake squeal, it can also be extended to other issues. By applying this methodology, while designing brake system, corrective and iterative design steps can be initiated and implemented for betterment of component design. The proposed methodology will also remove surprises during the system deployment. Continued research in this direction can bring about more comprehensive and appropriate guide lines for designers.

The predicted results show that brake squeal propensity can be reduced by increasing Young's modulus of the back plate and modifying the shape of friction material by adding chamfer on both sides of friction material and by introducing slot configurations. The combined approach of modeling brake squeal using CEA and DOE is found to be statistically adequate through verification trials. This combined approach will be useful in the design stage of the disc brake. The target of future work will be to develop the brake model such as considering full brake assembly, including effect of material damping, wear effect, and pressure contact distribution.

\section{Acknowledgments}

We would like to thank Prof. (Dr.) A. Elayaperumal, Department of Mechanical Engineering, Anna University, for his helpful comments and recommendations about frequency response measurements of the brake system. We would also like to extend our sincere thanks to Prof. (Dr.) Latha Nagendran, Anna University and the reviewers of this paper for their valuable comments and suggestions.

\section{References}

ABAQUS Analysis User’s Manual, Version 6.6-1. ABAQUS, Inc. 2006.

AbuBakar, A.R., and Ouyang, H. 2006. Complex eigenvalue analysis and dynamic transient analysis in predicting disc brake squeal. Int. J Vehicle Noise Vibration, Vol. 2, No. 2, pp. 143-155.

Akay, A. 2002. Acoustic of friction. Journal of Acoustical Society of America, Vol. 111, No. 4, pp. 1525-1548.

Bajer, A., Belsky, V., and Zeng, L. J. 2003. Combining a nonlinear static analysis and complex eigenvalue extraction in brake squeal simulation. S.A.E Technical Paper 2003-01-3349.

Blaschke P., Tan M., and Wang A. 2000. On the analysis of brake squeal propensity using finite element method. SAE Paper, 2000-01-2765.

Brooks, P. C., Crolla, D. A., Lang, A.M., Schafer, D. R. 1993. Eigenvalue sensitivity analysis applied to disc brake squeal. Proc. IMechE, C444/004, pp. 135-143.

Chakrabotry, G., Jearsiripongkul, T., von Wagner, U., Hagedorn, P. A New model for a floating caliper disc-brake and active squeal control. VDI-Bericht, Vol. 1736, pp. 93-102.

Chowdhary, H. V., Bajaj, A. K. and Krousgrill, C. M. 2001. An analytical approach to model disc brake system for squeal prediction. DETC2001/VIB-21560, ASME, pp. 1-10.

Dai Y. and Lim T.C.. 2008. Suppression of brake squeal noise applying finite element brake and pad model enhanced by spectralbased assurance criteria. Applied Acoustics, Vol. 69, pp. 196-214.

Dunlap, K.B., Riehle, M.A., and Longhouse, R.E. 1999. An investigative overview of automotive disc brake noise, SAE Paper: 1999-01-0142.

Hu, Y., Mahajan, S., and Zhang, K. 1999. Brake squeal DOE using nonlinear transient analysis. SAE Paper 1999-01-1737.

Ibrahim, R.A. 1994. Friction-induced vibration, chatter, squeal and chaos, part II: dynamics and modelling, ASME Applied Mechanics Reviews, Vol. 47, pp. 227-259.

Joe, Y.G., Cha, B.G., Sim, H.J., Lee, H.J., Oh, J.E. 2008. Analysis of disc brake instability due to friction-induced vibration using a distributed parameter model, International Journal of Automotive Technology, Vol. 9, No. 2, pp. 161-171.

Kinkaid, N.M., Reilly, O.M., and Papadopoulos, P. 2003. Automotive disc brake squeal, Journal of Sound and Vibration, Vol. 267, pp. 105-166.

Lee, Y. S., Brooks, P. C., Barton, D. C., and Crolla, D. A. 1998. A study of disc brake squeal propensity using a parametric finite element model, Proc. Instn Mech. Engrs, paper 98, pp. 191-201.

Liles, G. D. 1989. Analysis of disc brake squeal using finite element methods, SAE paper 891150, pp. 1138-1146.

Liu, P., Zheng, H., Cai, C., Wang, Y.Y., Lu, C., Ang, K.H., Liu, G.R. 2007. Analysis of disc brake squeal using the complex eigenvalue method, Applied Acoustics, Vol. 68, pp. 603-615.

Mario, T.J., Samir, N.Y., and Roberto J. 2008. Analysis of brake squeal noise using the finite element method: A parametric study. Applied Acoustics, Vol. 69, pp. 147-162.

Millner, N. An analysis of disc brake squeal. SAE Technical Paper, 1978, 780332.

Montgomery, D.C. 2005. Design and analysis of experiments. $5^{\text {th }}$ edition. Wiley, Singapore. 
Nouby, M. and Srinivasan, K. 2009. Parametric studies of disc brake squeal using finite element approach, Jurnal Mekanikal, (accepted for publication).

Nouby, M., and Srinivasan, K. 2009. Disc Brake squeal reduction through pad structural modifications. Proceedings of the International Conference on Recent and Emerging Advanced Technologies in Engineering, Kuala Lumpur.

Ouyang, H. and Mottershead, J.E. 1998. Friction-induced parametric resonances in disc: effect of a negative friction-velocity relationship, Journal of Sound and Vibration, Vol. 209, No. 2, pp. 251-264.

Papinniemi A, Lai JCS, Zhao, J. and Loader, L. 2002. Brake squeal: a literature review, Applied Acoustics, Vol. 63, pp. 391-400.

Shin, K., Brennan, M.J., Oh, J.-E., Harris, C.J. 2002. Analysis of disk brake noise using a two-degree-of-freedom model. Journal of Sound and Vibration, Vol. 254, No. 5, pp. 837-848.

Sinou, J. J., Thouverez, F., Je'ze'quel, L. 2003. Analysis of friction and instability by the center manifold theory for a non-linear sprag-slip model, Journal of Sound and Vibration, Vol. 265, No. 3, pp. 527-559.

Von Wagner, U., Jearsiripongkul, T., Vomstein, T., Chakrabotry, G., Hagedorn, P. 2003. Brake squeal: modelling and experiments, VDIBericht, Vol. 1749, pp. 173-186.

Von Wagner, U., Hochlenert, D., Jearsiripongkul, T., Hagedorn, P. 2004. Active control of brake squeal via “'Smart pads"'. SAE Paper 2004-01-2773.

\section{Biographical notes}

M. Nouby is a research scholar in the Department of Mechanical Engineering, Anna University, India since 2007. He received his B.Sc. and M.S. degrees from Department of Automotive and Tractor Engineering, Minia University, Egypt in 1999 and 2003 respectively. Prior to joining the faculty at Anna University, he worked as an assistant lecturer in Minia University from 2003 to 2007. His research interests are in the areas of Vehicle Dynamics, Finite Element Methods, Automotive Design, Noise and Vibration.

Dr. D. Mathivanan is a practicing engineer in the field of mechanical engineering. He obtained his B.E. (Mechanical) from GCT, Coimbatore, India in the year 1990. He received his M.E. (Manufacturing) and Ph.D. from Anna University, Chennai, India. He has international and national journal papers to his credit. His research areas are CAD, CAM, CAE and Plastics.

Dr. K. Srinivasan is one of the senior professors in the Department of Mechanical Engineering of Anna University. He has many international and national journal and conference papers to his credit. His current research interests are Tribology, Vibration and CNC machining.

Received December 2009

Accepted December 2009

Final acceptance in revised form December 2009 